\title{
Factors affecting the practice of seclusion in an acute mental health service in Southland, New Zealand
}

\author{
Stephen Tyrer, ${ }^{1}$ Jay Beckley, ${ }^{2}$ Digvijay Goel, ${ }^{2}$ Brian Dennis, $^{2}$ Brenda Martin ${ }^{2}$
}

The Psychiatrist (2012), 36, 214-218, doi: 10.1192/pb.bp.111.035790

${ }^{1}$ Newcastle University, UK; ${ }^{2}$ Mental Health Unit, Southland Hospital, Invercargill, New Zealand Correspondence to Stephen Tyrer (stephen.tyrer@ncl.ac.uk)

First received 21 Jun 2011, final revision 11 Jan 2012, accepted 7 Feb 2012

\begin{abstract}
Aims and method This study examined the frequency of seclusion intervention and factors associated with its use in the acute general adult psychiatric ward serving the Southland area of New Zealand. Details of the use of seclusion and relevant demographic data were collected over a 12-month period in 2007-2008.

Results During the study period there were 30 seclusion episodes involving 23 patients. The median duration of seclusion was 17 hours. The duration of seclusion was found to be inversely related to the treatment received during the period of isolation. Most patients under seclusion had a diagnosis of psychosis, and the nature of this was directly related to the Mental Health Act order applied.
\end{abstract}

Clinical implications The duration of seclusion in this study is long but compares with a similar study from elsewhere in New Zealand. The duration of treatment while in seclusion could be reduced if optimal treatment is given.

\section{Declaration of interest None.}

Seclusion is an intervention commonly used in psychiatry to manage acute behavioural disturbance, particularly physical aggression to others. ${ }^{1}$ The use of seclusion in psychiatric hospitals in New Zealand and Australia is frequent. The practice involves isolating individuals in a locked room from which they 'cannot freely exit'. ${ }^{2}$ According to New Zealand Health and Disability Services, seclusion should only be used as a last resort, and only if the person is presenting a risk to themselves or others. ${ }^{3}$

There is continuing debate about the value of seclusion in mental health services and this study was initiated to determine the exact frequency of this procedure and factors associated with its use in a remote area of New Zealand. The use of seclusion was examined over a 12-month period in a 20-bed general adult acute psychiatric unit in the mental health unit at Southland Hospital in Invercargill. The unit serves a population of 107000 people of whom $15 \%$ are of Maori origin. It has two purpose-built seclusion rooms adjacent to the two main wards in the hospital. These rooms are locked off physically from the two acute adult wards but the care is fully integrated as the same key staff are responsible for the patients in both settings.

In addition to determining the frequency of seclusion over the year of the study, the demographic characteristics of those in seclusion, the reasons for seclusion and the factors that determined the length of time spent in isolation were examined. A seclusion episode was recorded whenever a patient was transferred to the specialised locked facility. If a patient was secluded more than once, each episode was treated as a separate event.

\section{Method}

Information on all patients requiring seclusion during the 1year study period, from 1 August 2007 to 31 July 2008, was collected. The reasons for seclusion were recorded by examining the events preceding the episode. The duration of seclusion and when this was initiated were also determined. The diagnosis of each patient, the Mental Health Act section applied at the time and the ethnicity and gender of the patients involved were recorded. Any pro re nata (p.r.n.) medication administered before the seclusion episode was initiated was noted. The drug treatment received during the seclusion episode was subsequently assessed independently by two of the psychiatrist authors (S.T. and D.G.), and the adequacy of this treatment was determined according to the recommendations given in the Maudsley Prescribing Guidelines. ${ }^{4}$ If the drug treatment given at the times of reviews in seclusion was in the doses recommended in the Maudsley guidelines, the adequacy of treatment was recorded as good. If the treatment given was not covered in these guidelines or if the dosage of the drugs given was more than $50 \%$ less than recommended, with due allowance for the age of the patient, the quality of treatment was determined inadequate. The chapters referred to in these guidelines were concerned mainly with the treatment of acutely disturbed patients with behavioural problems, but reference was also made to the treatment of acute mania, antipsychotic polypharmacy and drug treatment of depression. Where there was disagreement, which only occurred on one occasion, the most favourable assessment of the 
management received was recorded. Treatments other than medication were not assessed. Attempts to de-escalate and defuse behavioural disturbance were made in many cases but these interventions were not recorded.

This audit was carried out as part of a service quality assurance procedure. Monitoring of seclusion levels was seen as relevant to good-quality management of patients so no specific consent was sought from those involved as there was no direct patient contact during the investigation. Statistical analysis was performed using the Statistical Package for Social Sciences (SPSS) version 17 for Windows. The distribution of the length of time spent in seclusion was found to be positively skewed and both log transformation and inverse log transformation were carried out to attempt to convert the data to a normal distribution. The distributions revealed using both these techniques still did not fulfil the conditions for normality and so nonparametric statistics were performed. To minimise the influence of outliers, the period in seclusion was grouped into 9 separate categories, each lasting 12 hours, and analysis was performed on these data. Where the goodness of fit of the data was justified for categorical data, a $\chi^{2}$-test with Yates' correction or Fisher's exact test was used.

\section{Results}

During the 12-month period of data collection there were 254 patients admitted to the mental health unit. Of these, 56 had multiple admissions during the study, 1 on six occasions, and in total there were 333 separate admission episodes. In total, 23 patients were secluded in 30 episodes during this period; some patients were secluded more than once. Thus, of all patients admitted to the unit, $9.1 \%$ were secluded. Table 1 shows the frequency of seclusion episodes and patient characteristics. The median age of those secluded was 34.5 years, with males non-significantly older than females (37.0 v. 31.0 years).

Significantly more males than females were secluded. None of the 5 females were secluded more than once, whereas 5 of the 18 males were secluded twice or more. Patients of Maori origin and those of continental European nationality were secluded more often than the indigenous New Zealand Pākehā (White) population. Those with a diagnosis of schizoaffective disorder, schizophrenia and bipolar affective disorder were much more likely to be secluded than patients in other diagnostic categories. All five of the patients with bipolar affective disorder who were secluded were in the manic stage at the time. No relationship was found between diagnosis and event leading to seclusion or period of time in seclusion. There was a significant relationship between Mental Health Act status and diagnosis. All but one of the five patients on Sections 29 or 30 (both restrictive orders applied by a court, lasting for 6 months or longer, that required the patient to be reviewed regularly) had a diagnosis of schizophrenia (the other patient had schizoaffective disorder), whereas the five patients with mania were all on Sections 11 or 13 (short-term orders lasting for 2 weeks or less applied by a consultant psychiatrist) $(P<0.05$; Fisher's exact test). The four Europeans were all detained under Sections 11 or 13.
Three-quarters of the seclusion episodes were initiated because of considerable marked agitation manifested by the patient, usually associated with threats of assault. There was a tendency for younger people to have physically assaulted someone before being secluded but this only occurred on five occasions. Half of all the seclusion episodes occurred during the evening shift, between 16:00 and 24:00, with exactly a third of episodes manifest at the time of the morning shift, between 08:00 and 16:00. In addition to seclusion, usually occurring just before the event, medication was given on seven occasions, either orally or intramuscularly in an attempt to defuse the behaviour exhibited. Receipt of this p.r.n. medication did not relate to gender, ethnicity, diagnosis or outcome.

The frequency of implementing seclusion was similar during the summer, autumn and winter but during the spring months seclusion was only carried out on three occasions (Table 2). With regard to days of the week when seclusion was used, six seclusion episodes were initiated on Mondays and Thursdays but only two episodes were

\begin{tabular}{|c|c|c|c|}
\hline \multicolumn{4}{|c|}{$\begin{array}{l}\text { Demographic and diagnostic characteristics } \\
\text { of the cohort of patients }\end{array}$} \\
\hline Characteristic & $\begin{array}{c}\text { Total, } \\
n\end{array}$ & $\begin{array}{l}\text { Secluded, } \\
\quad n(\%)\end{array}$ & Significance \\
\hline \multicolumn{4}{|l|}{ Gender } \\
\hline Male & 138 & $18(13)$ & $P<0.05$ \\
\hline Female & 116 & $5(4)$ & $1<-0.0$ \\
\hline \multicolumn{4}{|l|}{ Ethnicity } \\
\hline New Zealand Pakeha & 186 & $10(5)$ & \\
\hline Maori & 44 & $8(18)$ & $P<0.05^{a}$ \\
\hline European & 16 & $4(25)$ & $P<0.05^{a}$ \\
\hline Other & 8 & $1(13)$ & \\
\hline \multicolumn{4}{|l|}{ Diagnosis } \\
\hline Schizophrenia & 44 & $8(18)$ & $P<0.0001^{b}$ \\
\hline Schizoaffective disorder & 12 & $5(42)$ & $P<0.0001^{\mathrm{b}}$ \\
\hline Bipolar disorder & 40 & $5(13)$ & $P<0.0001^{b}$ \\
\hline Major depression & 38 & $0(0)$ & \\
\hline Other psychoses & 6 & $0(0)$ & \\
\hline Substance misuse ${ }^{c}$ & 12 & $1(8)$ & \\
\hline Borderline personality & & & \\
\hline disorder & 8 & $1(13)$ & \\
\hline Other & 94 & $3(3)$ & \\
\hline
\end{tabular}

a. This level of significance refers to each of these ethnic groups in comparison with the New Zealand Pakeha group.

b. This comparison refers to the first three diagnostic categories combined with the remainder.

c. For patients with substance misuse who were dually diagnosed the accompanying psychiatric diagnosis was included as the prime diagnosis. Three of these patients had a diagnosis of mania.

Table 2 Seasonal frequency of seclusion events

\begin{tabular}{lccc} 
& $\begin{array}{c}\text { Episodes of } \\
\text { Seclusion, } n\end{array}$ & $\begin{array}{c}\text { Total } \\
\text { percentage }\end{array}$ & Significance \\
\hline $\begin{array}{l}\text { Summer } \\
\text { (December-February) }\end{array}$ & 7 & 23 & $\mathrm{~ns}$ \\
\hline Autumn (March-May) & 9 & 30 & $\mathrm{~ns}$ \\
\hline Winter (June-August) & 11 & 37 & $\mathrm{~ns}$ \\
\hline $\begin{array}{l}\text { Spring } \\
\text { (September-November) }\end{array}$ & 3 & 10 & $\mathrm{~ns}$ \\
\hline
\end{tabular}

ns, not significant.

a. Seasons as experienced in New Zealand. 


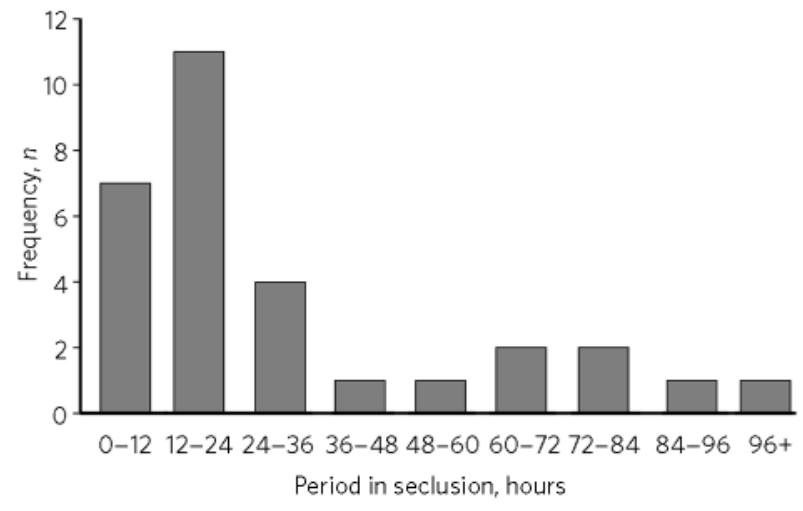

Fig. 1 Duration of seclusion episodes.

recorded on Sundays and Tuesdays, with intermediate figures for the other days.

The median time spent in seclusion was 17 hours (s.d. =28.0; mean 30.5; minimum 1.45, maximum 99). The median duration of seclusion initiated during the day shift seemed comparatively longer ( 24.2 hours) than seclusion initiated during the evening (16 hours) and night (9.15 hours) shifts, but this difference was not significant. Most $(60 \%)$ of the patients in the secluded group were secluded only once. Thirteen per cent (4 patients) were secluded twice and one patient was secluded four times. Fig. 1 illustrates the duration of seclusion events.

To determine if there were any variables that contributed to the duration of the period in seclusion, a logistic regression was originally considered but was not performed because the distribution of the data was nonparametric. Therefore, each independent variable that could possibly affect the duration of seclusion was selected and the relationship between each variable and the dependent variable of seclusion duration was determined. The association between the putative determining factors and the outcome of seclusion was studied using $\chi^{2}$-tests and the Mann-Whitney $U$ statistic. The independent variables selected for this analysis included suitability of medication in seclusion, age, gender, ethnicity, diagnosis, event preceding the seclusion episode, time of seclusion and whether p.r.n. medication was given before the seclusion episode.

The results of this analysis revealed only one significant factor contributing to the length of time spent in seclusion, namely the treatment prescribed while in the seclusion room $(P=0.045$; Mann-Whitney $U$ ). The treatment given corresponded to that recommended in the Maudsley guidelines in exactly half of all seclusion episodes so in $50 \%$ the treatment prescribed was below standard. Analysis of the data revealed that the median period of time spent in seclusion was 16.45 hours (s.d.=10.6; mean 18.5) for those who received treatment according to the Maudsley guidelines, whereas in those who received treatment unsupported by the recommendations in these guidelines the median duration of seclusion was 28.25 hours (s.d. $=34.3$; mean 42.6 ).

\section{Discussion}

The seclusion rate in this sample is lower than that measured in the North Island of New Zealand earlier in the decade in the Waikato study. In this investigation carried out in 2000 there were 129 seclusion episodes reported in an acute adult psychiatry unit over a 9-month period. ${ }^{5}$ The area concerned was over three times larger than the catchment area covered by the Southland Mental Health Unit and the figures represented a seclusion rate of 5.5 per annum for every 10000 people in the area covered. The equivalent figure for Southland in our study was 2.8 per annum for every 10000 persons. However, these figures may not be directly comparable as there was an interval of 8 years between the Waikato study and ours.

The Ministry of Health in New Zealand began to collect statistics on the use of seclusion in 2006. According to the 2009 report, review of these indicates significant differences in the frequency and duration of seclusion used when different district health boards are compared. ${ }^{6}$ This report showed that between 1 January and 31 December 2008, covering the majority of time of the present study, 6424 patients spent time in New Zealand adult mental health units and $16 \%$ (1023) of these individuals were secluded, substantially more than the $9.1 \%$ in this investigation. Nationally, most episodes of seclusion lasted less than 3 hours.

There is a significant variance of seclusion data across district health boards but there have been no studies investigating why this is so. However, it seems likely that the introduction of psychiatric intensive care units (PICUs) in certain areas where these have been provided contributes to a lower frequency of seclusion. One of us (J.B.) now works in Wellington where there is a PICU and seclusion in this unit is a relatively rare event. The nearest PICU to Invercargill is in Dunedin, which is 110 miles away. This unit has high occupancy rates and transporting disturbed patients (a 2- to 3-hour journey) is logistically difficult. The lack of provision of a PICU could possibly be a factor contributing to a higher rate of seclusion in Southland than would otherwise be the case.

Our finding that more males than females were secluded parallels reports from others. ${ }^{5}$ Patients of Maori and European nationality were more likely to be secluded than those of the New Zealand Pākehā (White) population who had been brought up in New Zealand. Our figures regarding the rate of seclusion of Maori patients are similar to those in the study carried out in Waikato, in the North Island of New Zealand, where $20 \%$ of all Maori patients admitted were secluded as opposed to $11 \%$ of patients of Pākehā origin. ${ }^{5}$ A quarter of the continental European patients were secluded in our study. The Southland Mental Health Unit catchment area includes Queenstown, which attracts a large number of European tourists. Three of the four Europeans secluded had developed manic illnesses and had a pre-existing bipolar affective disorder.

Diagnosis was related to the practice of seclusion. Most patients who were secluded had a psychotic illness, particularly schizophrenia, mania and schizoaffective disorder. Similar findings were noted in an earlier study. ${ }^{5}$ However, over $20 \%$ of the patients had a non-psychotic disorder, including substance misuse, adjustment disorder and conduct disorder.

The time of year when seclusion occurs has not been studied in great detail. In this small study there were no significant differences in the rates of seclusion according to 
the season. Similarly, in a study of violent episodes by psychiatric in-patients no seasonal change was noted. ${ }^{7}$ In a larger investigation carried out in a forensic psychiatry unit in Finland there were significantly more seclusion episodes in the summer months, starting in July and continuing until November. ${ }^{8}$

With regard to the day of the week when seclusion was initiated, fewer episodes occurred on a Sunday. It is likely that seclusion is less commonly implemented at weekends because of the reduction of formal programmes of activity and education at this time and because more patients are on leave during this period. This finding has been noted by others.,

On examining the actual episodes of seclusion, agitation, involving threats of assault to staff, patients or property, was recorded as the reason for seclusion in $75 \%$ of the episodes, whereas actual physical assault occurred in only $20 \%$ of the episodes. This latter figure compares with a higher frequency of $45 \%$ for assault in the Waikato study. ${ }^{5}$

The evening shift is the time of day when seclusion is most frequently implemented and half of all the episodes occurred between 16:00 and midnight. In the Waikato study a virtually identical figure (52\%) was noted for the evening shift. ${ }^{5}$

It is generally agreed that seclusion should be used for the least amount of time possible. The average duration reported by previous studies varies widely. The duration of seclusion in this study (median 17 hours) is long, but is similar to the period of seclusion noted in the Waikato investigation, where the median time of seclusion was 14 hours. ${ }^{5}$ In earlier studies on the length of time of seclusion episodes, Soloff \& Turner reported a median duration of 2.8 hours (mean 10.8, range 10 minutes-20 hours) in the USA, ${ }^{10}$ and Thompson found a median duration of 4.3 hours (range 10 minutes-25.5 hours) in the UK. ${ }^{11}$ These two investigations were carried out over two decades ago. More recent studies show a considerable reduction from these figures, ${ }^{12,13}$ after programmes were developed to reduce periods of isolation. The duration of seclusion episodes recorded in both our study and that from the Waikato study is considerably longer than in these investigations and suggests a different attitude to treatment approach.

In New Zealand, as is probably the case elsewhere, the length of time spent in seclusion is based on clinicians' assessments and the patients' response to intervention. Since deinstitutionalisation, patients in psychiatric hospitals have become more acutely ill and therefore are more challenging to treat. ${ }^{14}$ This is consistent with international evidence suggesting an increase of violence in psychiatric hospitals. ${ }^{15}$ It would therefore be expected that there would be an increase in the risk for being secluded or restrained when receiving treatment in a psychiatric hospital. Perhaps surprisingly this is not the case. According to some commentators, the reason why the duration of seclusion has decreased recently is because stricter regulations regarding this practice have been enforced. ${ }^{16,17}$ If this assumption is correct, tighter regulation on the use of seclusion in New Zealand could well lead to a reduction in the time spent in isolation.

With regard to factors associated with the use of seclusion, international studies suggest reasons for variation include differences in seclusion practice, the availability of intensive care and low-stimulus facilities, staff factors, geographical variations in prevalence and severity of mental illness, use of sedating psychotropic medication, and data collection or analysis errors. ${ }^{18}$ The reasons for the period of seclusion being prolonged in Southland may include reduction of staff numbers, particularly at night, ${ }^{5}$ and inadequate management. The undoubted fact of reduced night-time supervision may explain to some degree the longer period of seclusion experienced by patients secluded during the evening shift.

What may be more important is the treatment received when in seclusion. Our assessment of the treatment given showed that when treatment was perceived as inadequate the period in seclusion was correspondingly prolonged. The reasons for this could include changes in psychiatrist supervision during the long supervision, an inclination not to change the existing medication regime, concern about giving large doses of sedative drugs and inadequate knowledge of psychopharmacological and management techniques of the psychiatrists involved. It seems evident that more careful attention to prescribed guidelines would be of benefit.

This study supports the findings of an earlier study carried out in New Zealand showing that the duration of seclusion, when carried out in acute psychiatric in-patient units, is longer than in other countries. This investigation suggests that more appropriate management of patients while in seclusion could contribute to shorter periods of time in isolation.

\section{Acknowledgements}

We thank the staff of the Mental Health In-patient Unit at Southland Hospital for their assistance in contributing to this study and Dr Jonathan Tyrer, Genetic Epidemiology Group, Department of Oncology at Cambridge University, UK, for helpful statistical advice.

\section{About the authors}

Stephen Tyrer is an honorary senior lecturer at Newcastle University. Jay Beckley was a research assistant at Southland Mental Health Unit at the time of the study, and is now working as a mental health clinician at Capital and Coast District Health Board, Wellington, New Zealand. Digvijay Goel is a consultant psychiatrist working at Southland Mental Health Unit. Brian Dennis and Brenda Martin are both senior nurses at Southland Mental Health Unit.

\section{References}

1 Sullivan D, Wallis M, Lloyd C. Effects of patient-focused care on seclusion in a psychiatric intensive care unit. J Ther Rehabil 2004; 11: 503-8.

2 Meehan T, Vermeer C, Windsor C. Patients' perceptions of seclusion: a qualitative investigation. J Adv Nurs 2000; 31: 370-7.

3 New Zealand Ministry of Health. Health and Disability Services (Restraint Minimisation and Safe Practice) Standards. New Zealand Ministry of Health, 2008.

4 Taylor D, Paton C, Kerwin R. The Maudsley Prescribing Guidelines, 9th Edition. Informa Healthcare, 2007.

5 El-Badri SM, Mellsop G. A study of the use of seclusion in an acute psychiatric service. Aust N Z J Psychiatry 2002; 36: 399-403.

6 Office of the Director of Mental Health. Annual Report, 2008. New Zealand Ministry of Health, 2009. 
7 Noble P, Rodger S. Violence by psychiatric in-patients. Br J Psychiatry 1989; 155: 384-90.

8 Paavola P, Tiihonen J. Seasonal variation of seclusion incidents from violent and suicidal acts in forensic psychiatric patients. Int J Law Psychiatry 2010; 33: 27-34.

9 Rangecroft ME, Tyrer SP, Berney TP. The use of seclusion and emergency medication in a hospital for people with learning disability. $\mathrm{Br}$ Psychiatry 1997; 170: 273-7.

10 Soloff $P$, Turner SM. Patterns of seclusion: a prospective study. J Nerv Ment Dis 1981; 169: 37-44.

11 Thompson $\mathrm{P}$. The use of seclusion in psychiatric hospitals in the Newcastle area. Br J Psychiatry 1986; 149: 471-4.

12 Fisher WA. Elements of successful restraint and seclusion reduction programs and their application in a large, urban, state psychiatric hospital. J Psychiatr Pract 2003; 9: 7-15.
13 Smith GM, Davis RH, Bixler EO, Lin HM. Pennsylvania State Hospital system's seclusion and restraint reduction program. Psychiatr Serv 2005; 56: 1115-22.

14 Keski-Valkama A, Sailas E, Eronen M, Koivisto A-M, Lönnqvist J, Kaltiala-Heino R. A 15-year national follow-up: legislation is not enough to reduce the use of seclusion and restraint. Soc Psychiatry Psychiatr Epidemiol 2007; 42: 747-52.

15 Flannery RB, Juliano J, Cronin S, Walker A. Characteristics of assaultive psychiatric patients: fifteen-year analysis of the Assaulted Staff Action Program (ASAP). Psychiatr Quart 2006; 77: 239-49.

16 Currier G, Farley-Toombs C. Datapoints: use of restraint before and after implementation of the new HCFA rules. Psychiatr Serv 2002; 53: 138.

17 Donovan A, Plant R, Peller A, Siegel L, Martin A. Two-year trends in the use of seclusion and restraint among psychiatrically hospitalized youths. Psychiatr Serv 2003; 54: 987-93.

18 Livingstone A. Seclusion Practice: A Literature Review. Victorian Quality Council and Chief Psychiatrist's Quality Assurance Committee, 2007.

\title{
Predictors for retention in treatment with a UK community-based naltrexone programme for opioid dependence
}

\author{
Zubair A. Chaudhry, Javaid Sultan, ${ }^{2}$ Farrukh Alam ${ }^{1}$
}

The Psychiatrist (2012), 36, 218-224, doi: 10.1192/pb.bp.111.035063

${ }^{1}$ Central and North West London NHS Foundation Trust; ${ }^{2}$ Berkshire Healthcare NHS Foundation Trust

Correspondence to Zubair A Chaudhry (zubair.chaudhry@nhs.net)

First received 20 Apr 2011, final revision 17 Oct 2011, accepted 2 Dec 2012
Aims and method To evaluate the efficacy of naltrexone maintenance therapy in a community-based programme for opioid-dependent patients and to identify predictors for longer-term retention in treatment. A retrospective case-note study was conducted in 142 people dependent on opioids who had undergone detoxification and maintained adherence to naltrexone treatment for a minimum of 4 weeks. Social and clinical demographic factors during treatment were recorded using a standardised naltrexone monitoring scale. Efficacy was measured as retention in treatment, and potential predictors were examined using regression analysis.

Results Although there was overall low retention of patients in treatment, $55.6 \%$ of the patients remained in treatment for 4-8 weeks, and $29.6 \%$ of the patients remained in treatment for 17 weeks or more. Enhanced long-term retention in treatment was associated with Asian or other minority ethnic status, employment, parental supervision of naltrexone administration, less boredom, short duration of addiction, younger age, low alcohol intake and no cannabis use in univariate analyses. Short duration of opioid dependence syndrome (3 years) and low alcohol intake $(<10$ units/week) were significant independent predictors for longer-term retention in treatment in subsequent multivariate analysis.

Clinical implications Low alcohol intake and shorter duration of addiction were significant independent predictors for longer-term retention in treatment, but retention rates for naltrexone remain low overall. Additional psychosocial support may be needed to address these issues.

Declaration of interest None.
The National Institute for Health and Clinical Excellence (NICE) has reported that naltrexone is recommended as a treatment option in detoxified formerly opioid-dependent people who are highly motivated to remain on an abstinence programme. Naltrexone should be administered only under adequate supervision and after fully informing the patient of the potential adverse effects of treatment. Naltrexone should be given as part of a programme of supportive care. 
The effectiveness of naltrexone in preventing opioid misuse should be reviewed regularly, and discontinuation of naltrexone treatment should be considered if there is evidence of such misuse. The NICE committee was convinced of the clinical effectiveness of naltrexone treatment in a selected, highly motivated group of people. The NICE committee concluded that for people who preferred an abstinence programme, who were fully informed of the potential adverse effects and benefits of treatment, and who were highly motivated to remain on treatment, naltrexone treatment would fall within acceptable cost-effectiveness limits. ${ }^{1}$

According to Luty, naltrexone completely blocks the effects of opiates and acts as an 'insurance policy' against opiate use. ${ }^{2}$ Naltrexone can precipitate acute withdrawal and should be used only following abstinence from all opioids, including methadone. Treatment can be given daily or three times a week. Luty argues that naltrexone has not proven effective in treatment settings, although some investigators appear to have viewed it as a direct alternative to methadone rather than as an approach that can enable a completely opiate-free state; for example, in one trial, only 15 of 300 patients chose naltrexone instead of detoxification or methadone maintenance, and of those 15 participants, only 3 continued naltrexone for more than 2 months. ${ }^{2}$

Naltrexone is an opioid receptor antagonist used primarily as maintenance treatment in the management of opioid or alcohol dependence. As an antagonist, it does not provoke a biological response when it binds to the opioid receptors, but instead it blocks or dampens agonistmediated responses, blocking the euphoric effects of heroin and other opioids, helping patients to maintain abstinence from opioid drugs. ${ }^{3}$ A number of systemic reviews and meta-analyses have examined the efficacy of naltrexone in people who are dependent on opioid drugs. These reviews have concluded that naltrexone appears to have some benefit in the management of opioid dependence; however, the heterogeneity of trials makes objective evaluation difficult. ${ }^{3-7}$

The aim of this study was to use a retrospective casenote study to rigorously assess and identify other potential predictors for longer-term retention on naltrexone maintenance therapy. The case notes were also used to evaluate the overall rate of retention in treatment in a large UK community drug clinic.

\section{Method}

\section{Patients and treatment protocol}

We used a retrospective case-note study of 142 people treated with naltrexone therapy following opioid detoxification between April 1997 and December 2006. The protocol received approval from the local research ethics committee. All the patients included in the study were dependent on opioids and had completed successful opioid detoxification. Patients attending the clinic were assessed for suitability for naltrexone treatment. Consent for commencement of naltrexone therapy was obtained from all patients, their general practitioners (GPs) were informed, and each patient was given a naltrexone card to provide information to other health professionals.

Patients were seen every 2 weeks for the first month of treatment, and then every month. All patients completed a naltrexone monitoring scale (online Fig. DS1) at each visit. All patients who remained on naltrexone treatment had routine blood tests (full blood count, urea and electrolytes, liver function tests) every 3 months, or more frequently if indicated. Participants were assessed and followed up at the local community drug treatment centre. An afternoon session was dedicated as an 'abstinence promotion clinic', which involved a naloxone challenge to initiate naltrexone, reviewed patients prescribed naltrexone, asked patients to complete a naltrexone monitoring scale, and carried out random urine drug screening for all patients included in the study. Urine drug screening was conducted every 2 weeks, and liver function tests were conducted as indicated (every 6-12 weeks). Liaison with GPs and local providers and partners such as Drug and Alcohol Action Team was important to further develop a strategy for substance misuse treatment, in addition to primary prevention. The initial results of the study were fed back to patients who regularly attended follow-up appointments.

\section{Study procedures}

Clinical notes were examined for all eligible patients receiving naltrexone therapy following opioid detoxification during the study period of April 1997 to December 2006. The duration of the study allowed a large cohort to be recruited, thus increasing the power calculation. The following inclusion criteria were used:

- patients aged 18-65 years who were dependent on opioids and who had successfully completed detoxification

- resident of Ealing borough of London

- consent obtained before starting treatment with naltrexone therapy

- liver function tests within normal limits.

The following exclusion criteria were used:

- history of previous hypersensitivity

- on naltrexone for less than 3 weeks

- refusal to complete naltrexone monitoring scale questionnaire

- alcohol misuse or dependence

- abnormal liver biochemistry

- pregnant or planning pregnancy in the near future (all female participants had a pregnancy test before starting naltrexone).

Demographic details, family and relationship details and employment status were collected at the start of naltrexone treatment. A standardised questionnaire (naltrexone monitoring scale) was used to gather information about anxiety and depression symptoms, cravings, sleep disturbances, illicit drug use, and alcohol use and misuse at each medical out-patient assessment. Each category was scored on a scale of 0 (absent) to 10 (severe).

To assess the success of treatment and to evaluate predictors for retention in naltrexone treatment and successful abstinence from opioids, retention was categorized into three stages: 
- Stage I: 1-8 weeks

- Stage II: 9-16 weeks

- Stage III: 17 weeks.

\section{Statistical methods}

All relevant clinical case notes were reviewed for eligibility and the demographic details were anonymised to maintain patient confidentiality. We used SPSS version 10 for Windows for data entry and analysis.

The main efficacy outcome examined was whether or not patients progressed to stage III (treatment $\geqslant 17$ weeks). This was measured on a categorical scale as 'yes' or 'no'. The aim of the subsequent analysis was to examine which factors had an influence on this outcome.

At analysis, the scores from the naltrexone monitoring scale were simplified as follows:

- absent (0): symptoms not present, or normal, or no illicit drug use

- mild/low (1-3): mild symptoms or occasional illicit drug use (1-3 days/week)

- moderate (4-7): moderate symptoms or frequent illicit drug use (3-5 days/week)

- severe/high (8-10): severe or worst ever symptoms or daily illicit drug use (6-7 days/week).

The effect of each variable on the outcome (retention in treatment to stage III) was examined using logistic regression. The analysis of the data was performed in two stages. First, the individual effect of each variable was examined separately in a series of univariate analyses. Then the joint effects of the factors on the outcome were examined together in a multivariate analysis.

An advantage of the multivariate analysis was that the effect of each variable on the outcome is adjusted for the effect of the other variables, giving a better view of the underlying factors influencing the outcome. Only factors that showed evidence of a significant effect in the univariate analyses $(P<0.2)$ were included in the multivariate analysis. A backward selection procedure was used to determine the final model. This method involved removing non-significant variables from the analysis one by one until all remaining variables were statistically significant.

A number of the variables were measured on a categorical scale. As there were a relatively small number of participants in some groups, to increase the power of the study we combined some similar groups for the purposes of analysis.

\section{Results}

\section{Patients' characteristics}

Over the study period, 220 patients successfully achieved opioid detoxification and were prescribed naltrexone at the community drug treatment centre. Of these, 142 patients fulfilled the necessary criteria to be included in the study, and 78 patients were excluded from the study because of the exclusion criteria and insufficient data. The mean age of the study population was 26.4 years (range 17-61). The mean duration of addiction was 5.5 years (range 1-22). The 'typical' patient treated at the centre was an unmarried Asian male in his early 20s (Table 1).

\begin{tabular}{lc}
\multicolumn{2}{l}{ Table 1 Sociodemographic characteristics } \\
Variable & $n(\%)$ \\
\hline Age, years & \\
$\leqslant 21$ & $40(28.2)$ \\
$22-26$ & $50(35.2)$ \\
$27-31$ & $24(16.9)$ \\
$32-37$ & $12(8.5)$ \\
$38-42$ & $8(5.6)$ \\
$\geqslant 43$ & $8(5.6)$ \\
\hline Gender & \\
Male & $133(93.7)$ \\
Female & $9(6.3)$ \\
\hline Marital status & \\
Unmarried & $105(73.9)$ \\
Married & $31(21.8)$ \\
Not known & $6(4.2)$ \\
\hline Ethnic group & \\
White & $36(25.4)$ \\
Asian ${ }^{a}$ & $100(70.4)$ \\
Other & $6(4.2)$ \\
\hline Duration of addiction, years & \\
$\leqslant 1$ & $10(7.0)$ \\
$2-5$ & $85(59.9)$ \\
$6-9$ & $27(19.0)$ \\
$10-14$ & $9(6.3)$ \\
$15-18$ & $5(3.5)$ \\
$\geqslant 19$ & $6(4.2)$ \\
\hline
\end{tabular}

a For this study, we used the term 'Asian' to mean South-East Asian, including Indian, Pakistani, Sri Lankan and Bangladeshi people.

It is noteworthy that the majority of patients successfully recruited in the study were from Southall, a ward of the London borough of Ealing with a large population of people with an Indian background. Recent estimates suggest approximately $80 \%$ of the Southall population is Asian or British Asian. The 2001 census indicated the Southall ward population was $75.5 \%$ Asian or British Asian, compared with $24.53 \%$ in the London borough of Ealing.

\section{Opioid detoxification}

The majority of the patients $(n=106 ; 74.6 \%)$ completed successful detoxification in the out-patient or community setting. Overall, 32 patients $(22.5 \%)$ required in-patient treatment to complete detoxification, which included 9 patients (6.3\%) receiving private in-patient treatment, primarily by undergoing rapid opiate detoxification. A small percentage of patients $(2.8 \%)$ completed self-detoxification in the home environment.

The patients were treated with a number of different detoxification regimens: 86 patients (60.6\%) accomplished successful detoxification with buprenorphine as outpatients or in-patients; 30 patients (21.1\%) achieved detoxification with lofexidine; 10 patients (7\%) completed detoxification using methadone; and 16 patients (11.3\%) used other methods (dihydrocodeine, self-detoxification or combination medications, e.g. rapid opiate detoxification). To ensure the absence of opioid use and to prevent a severe withdrawal state related to naltrexone use, a naloxone challenge was used in 114 patients (80.3\%). 


\section{Naltrexone maintenance}

Maintenance treatment with oral naltrexone was given under supervision where possible: 83 patients (58.5\% of cases) were supervised by their parents; 37 patients $(26.1 \%)$ were supervised by their partner; 4 patients $(2.8 \%)$ were supervised by a sibling or friend; 11 patients (7.7\%) selfmedicated with naltrexone; and details of supervision were not known for 7 (4.9\%) patients.

\section{Retention in treatment}

The majority of the patients $(n=79 ; 55.6 \%)$ remained on naltrexone treatment for 4-8 weeks, and 42 patients (29.6\%) remained on treatment for at least 17 weeks (Table 2). The maximum treatment duration at the time of analysis was in excess of 72 weeks.

Reasons for discontinuing naltrexone treatment included lack of supervision, dislike of taking tablets, and lack of motivation to remain abstinent; in many cases, however, no reason was given for discontinuing naltrexone treatment. Most of the patients who left within the first 8 weeks of naltrexone treatment exited the service without prior warning. The most likely presumption was relapse, but other reasons include side-effects and dislike of giving control (through supervised naltrexone administration) to their partner or a relative. The most commonly reported adverse effects were nausea, abdominal pain, nervousness, sleeping difficulties, headache, reduced energy, joint and muscle pain, and sexual dysfunction. A rare laboratory finding was abnormal liver function tests.

\section{Potential predictors for long-term retention on naltrexone}

\section{Univariate analysis}

Progression to stage III (naltrexone maintenance treatment for at least 17 weeks) was used as an indicator of successful control of opioid dependence. The individual effects of each variable on progression to stage III were examined separately using logistic regression. The results, summarised in Table 3, indicate that when examined separately, eight different sociodemographic and addiction-related parameters had a statistically significant effect influencing long-term naltrexone treatment (stage III use).

The results for ethnicity indicate that Asian people were more likely than White people to continue to stage III $(P=0.01)$. The odds of continuing to stage III were more than four times higher for Asian patients when compared with White patients.

\begin{tabular}{|lc|}
\hline \multicolumn{2}{|l|}{ Table 2 Retention in naltrexone treatment } \\
Variable & $n(\%)$ \\
\hline Retention in treatment, weeks \\
$4-8$ weeks \\
$9-20$ weeks & $79(55.6)$ \\
$21-36$ weeks & $21(14.8)$ \\
$37-52$ weeks & $30(21.1)$ \\
$53-72+$ weeks & $7(4.9)$ \\
Retention in treatment by stage & $5(3.5)$ \\
Stage I (1-8 weeks) & $79(55.6)$ \\
Stage II (9-16 weeks) & $21(14.8)$ \\
Stage III ( $\geqslant 17$ weeks) & $42(29.6)$ \\
\hline
\end{tabular}

Employment status analysis indicate that people who were employed or students were nearly three times more likely to achieve long-term naltrexone treatment compared with people who were unemployed $(P=0.01)$.

People who rarely reported feeling bored were more likely to continue to stage III $(P=0.04)$. The odds of continuing to stage III were more than three times higher for people who were never or only occasionally bored compared with people who were bored most of the time. There was also some evidence for a positive effect of motivation, but this result was of borderline statistical significance $(P=0.05)$.

When alcohol intake was examined, there was little difference between the patients who did not drink alcohol and the patients who consumed a small number of units per week. Patients with an alcohol consumption of more than 10 units per week, however, were less likely to continue to stage III $(P=0.01)$. The odds of maintaining on naltrexone therapy to stage III were three times higher in patients who did not drink alcohol compared with patients with heavy alcohol consumption.

The results for cannabis use show that the patients with occasional, frequent or daily cannabis use were less likely to continue on naltrexone treatment than the patients who did not use cannabis $(P=0.04)$.

The results for supervision indicate that the patients living with and having treatment supervised by their parents were more likely to continue to stage III than the patients who were supported by their partner or undergoing self-treatment without supervision.

Addiction duration was a highly significant factor, with a longer duration associated with a decreased likelihood of continuing to stage III $(P=0.008)$.

Age was another significant factor, with younger patients being more likely to continue $(P=0.03)$. A 10-year increase in age was associated with the odds of continuing to stage III halving.

\section{Multivariate analysis}

The multivariate analysis indicated that only alcohol and addiction duration were statistically significant independent predictors for continuation to stage III (Table 4). After adjusting for these two factors, there was no evidence of an effect of ethnicity, employment, boredom, cannabis, supervision or age on continuing to stage III.

There was only a small difference between patients drinking no alcohol and patients drinking less than 10 units per week. The odds of retention in treatment to stage III were over three times smaller in patients who drank 10-40 units of alcohol per week compared with those who drank no alcohol.

The multivariate analysis determined that longer addiction duration was associated with a decreased likelihood of continuing to stage III. The odds of patients with addiction duration of 7 or more years continuing to stage III were a seventh of the odds of patients addicted for 3 years or less continuing to stage III. 


\begin{tabular}{|c|c|c|c|c|}
\hline Variable & $\begin{array}{c}\text { Did not progress } \\
n(\%)\end{array}$ & $\begin{array}{c}\text { Progressed to stage III } \\
n(\%)\end{array}$ & OR $(95 \% \mathrm{Cl})$ & $P$ \\
\hline $\begin{array}{l}\text { Gender } \\
\text { Male } \\
\text { Female }\end{array}$ & $\begin{array}{r}93(70) \\
7(78) \\
\end{array}$ & $\begin{array}{r}39(30) \\
2(22) \\
\end{array}$ & $\begin{array}{c}1 \\
0.68(0.14-3.43) \\
\end{array}$ & 0.64 \\
\hline $\begin{array}{l}\text { Marital status } \\
\text { Unmarried } \\
\text { Married }\end{array}$ & $\begin{array}{l}70(67) \\
24(77)\end{array}$ & $\begin{array}{r}34(33) \\
7(23)\end{array}$ & $\begin{array}{c}1 \\
0.60(0.24-1.53)\end{array}$ & 0.29 \\
\hline $\begin{array}{l}\text { Ethnicity } \\
\text { White } \\
\text { Asian or other }\end{array}$ & $\begin{array}{l}32(89) \\
68(65)\end{array}$ & $\begin{array}{r}4(11) \\
37(35)\end{array}$ & $\begin{array}{c}1 \\
4.36(1.43-13.3)\end{array}$ & 0.01 \\
\hline $\begin{array}{l}\text { Employment status } \\
\text { Unemployed } \\
\text { Employed or student }\end{array}$ & $\begin{array}{l}83(76) \\
17(53)\end{array}$ & $\begin{array}{l}26(24) \\
15(47)\end{array}$ & $2.86(1.24-6.41)$ & 0.01 \\
\hline $\begin{array}{l}\text { Boredom } \\
\text { None or occasional } \\
\text { Frequent } \\
\text { Most of the time }\end{array}$ & $\begin{array}{l}16(53) \\
41(72) \\
43(80)\end{array}$ & $\begin{array}{l}14(47) \\
16(28) \\
11(20)\end{array}$ & $\begin{array}{c}1 \\
0.44(0.18-1.12) \\
0.29(0.11-0.78)\end{array}$ & 0.04 \\
\hline $\begin{array}{l}\text { Motivation } \\
\text { Very good } \\
\text { Fair or poor }\end{array}$ & $\begin{array}{l}63(66) \\
37(82)\end{array}$ & $\begin{array}{r}33(34) \\
8(18)\end{array}$ & $\begin{array}{c}1 \\
0.41(0.17-0.99)\end{array}$ & 0.05 \\
\hline $\begin{array}{l}\text { Sleep disturbance } \\
\text { Nil or mild } \\
\text { Moderate } \\
\text { Severe }\end{array}$ & $\begin{array}{l}38(69) \\
38(72) \\
24(73)\end{array}$ & $\begin{array}{r}17(31) \\
15(28) \\
9(27)\end{array}$ & $\begin{array}{c}1 \\
0.88(0.39-2.02) \\
0.83(0.32-2.18)\end{array}$ & 0.92 \\
\hline $\begin{array}{l}\text { Alcohol intake } \\
\text { None } \\
<10 \text { units/week } \\
10-40 \text { units/week }\end{array}$ & $\begin{array}{l}33(35) \\
23(59) \\
44(86)\end{array}$ & $\begin{array}{r}18(35) \\
16(41) \\
7(14)\end{array}$ & $\begin{array}{c}1 \\
1.27(0.54-3.01) \\
0.29(0.11-0.78)\end{array}$ & 0.01 \\
\hline $\begin{array}{l}\text { Cannabis use } \\
\text { None } \\
\text { Occasional } \\
\text { Frequent or daily }\end{array}$ & $\begin{array}{l}27(57) \\
38(81) \\
35(75)\end{array}$ & $\begin{array}{r}20(43) \\
9(19) \\
12(26)\end{array}$ & $\begin{array}{c}1 \\
0.32(0.12-0.71) \\
0.46(0.19-1.11)\end{array}$ & 0.04 \\
\hline $\begin{array}{l}\text { Cocaine use } \\
\text { None } \\
\text { Occasional or frequent }\end{array}$ & $\begin{array}{l}93(72) \\
7(64)\end{array}$ & $\begin{array}{r}37(28) \\
4(36)\end{array}$ & $\begin{array}{c}1 \\
1.44(0.40-5.20)\end{array}$ & 0.58 \\
\hline $\begin{array}{l}\text { Supervision } \\
\text { Parent } \\
\text { Partner } \\
\text { Self or other }\end{array}$ & $\begin{array}{l}50(61) \\
31(84) \\
12(80)\end{array}$ & $\begin{array}{r}32(39) \\
6(16) \\
3(20)\end{array}$ & $\begin{array}{c}1 \\
0.30(0.11-0.81) \\
0.39(0.10-1.49)\end{array}$ & 0.03 \\
\hline $\begin{array}{l}\text { Addiction duration, years } \\
\begin{array}{l}1-3 \\
4-6 \\
\geqslant 7\end{array}\end{array}$ & $\begin{array}{l}34(59) \\
34(71) \\
32(91)\end{array}$ & $\begin{array}{c}24(41) \\
14(29) \\
3(9)\end{array}$ & $\begin{array}{c}1 \\
0.58(0.26-1.31) \\
0.13(0.04-0.48)\end{array}$ & 0.008 \\
\hline $\mathrm{Age}^{a}$ & 27 (8) & $24(5)$ & $0.51(0.27-0.94)$ & 0.03 \\
\hline
\end{tabular}

${ }^{a}$ Odds ratios given for a 10-year increase in age.

\section{Discussion}

One key finding from this study was the low retention in treatment for patients receiving naltrexone maintenance in a community setting: only $29.6 \%$ of patients remained in treatment for 17 weeks or more. The multivariate analysis identified only two significant independent predictors for longer-term retention in treatment: short duration of addiction ( $\leqslant 3$ years) and no or only low intake of alcohol $(<10$ units/week).

There were limitations associated with the study methodology, which should be taken into consideration. The analyses were retrospective in nature, and the sample size was relatively small, especially in view of the number of different variables evaluated. The analysis was conducted on 142 of 220 people dependent on opioids who were initiated on naltrexone treatment at the treatment centre during the study period. The people excluded from the evaluation may have revealed useful information on predictors for longerterm retention in treatment, but the population analysed reflects the patients with sufficient motivation to remain on treatment for at least 4 weeks - that is, the relevant patient population for the community-based clinical treatment setting.

The outcome measure to assess efficacy of naltrexone in the community setting was retention in treatment. In this study, of the 142 evaluable patients, $55.6 \%$ remained in 


Table $4 \begin{aligned} & \text { Independent predictors for successful long-term } \\
& \text { retention in treatment (progression to stage III) } \\
& \text { identified through multivariate analysis }\end{aligned}$
\begin{tabular}{lcc} 
Variable & OR $(95 \% \mathrm{Cl})$ & $P$ \\
\hline $\begin{array}{l}\text { Alcohol use } \\
\text { Nil }\end{array}$ & 1 & \\
$<10$ units/week & $1.36(0.55-3.36)$ & \\
$10-40$ units/week & $0.31(0.11-0.87)$ & 0.02 \\
\hline $\begin{array}{l}\text { Duration of addiction, years } \\
1-3\end{array}$ & 1 & \\
$4-6$ & $0.53(0.23-1.24)$ & \\
$\geqslant 7$ & $0.14(0.04-0.52)$ & 0.01 \\
\end{tabular}

treatment for only 4-8 weeks and $29.6 \%$ remained in treatment for 17 weeks or more (stage III). It could be argued that since 220 patients initiated naltrexone treatment following opioid detoxification, the retention in treatment for 17 weeks or more for patients on the programme was even lower $(42 / 220,19.1 \%)$.

These results are lower than those recorded in naltrexone clinical trials where the mean period for retention in treatment has been 17-30 weeks. ${ }^{8,9}$ The results from this study, however, are broadly similar to those achieved in a US community-based programme using behavioural therapy to augment naltrexone; ${ }^{10}$ in this study, retention in treatment for 36 patients dependent on heroin was $69.4 \%$ at 4 weeks, $44.4 \%$ at 12 weeks and $22.2 \%$ at 24 weeks. A public out-patient clinic in Australia analysed outcomes in 981 patients and reported a mean retention period of 9 weeks. ${ }^{11}$

In view of the relatively low long-term rates of retention in treatment achieved with naltrexone in a community setting, it is important to identify which patient subgroups are most likely to benefit from naltrexone treatment and which may need enhanced support to achieve abstinence despite fulfilling the treatment criteria (e.g. strong motivation, availability of supervision of treatment).

Review of the literature suggests very few studies have identified potential predictors for favourable outcome with naltrexone therapy. One early US study determined that patients in employment or married at the start of naltrexone treatment were more likely to stay in treatment for longer. ${ }^{12}$ A more recent US study reported that on multiple regression analysis, poorer outcome (shorter retention in treatment) was associated with methadone use and heavier use of heroin before treatment. ${ }^{13}$ A study from Spain found that men had a better prognosis than women: for 1432 people dependent on opioids (83.1\% males, $16.9 \%$ females) receiving naltrexone treatment over a period of 12 years, a significantly higher 1-year retention rate was found for men than for women (30.9\% v. 23.9\%, $P=0.0038)$. The authors concluded that these differences were due to sociocultural differences, with women having less economic independence, having an addict as a partner, or having less help from their partner. ${ }^{14}$

The premise for this retrospective analysis was that Asian people appeared to have a better outcome on naltrexone treatment compared with White people. Asian people constituted just over $70 \%$ of the patients enrolled into this naltrexone maintenance programme. Univariate analysis found that Asian and other minority ethnic people were significantly more likely than White people to achieve successful retention in treatment, being over four times more likely to be in treatment at 17 weeks or more. Possible reasons for a favourable outcome in Asian people include the following:

- family support during treatment, especially supervisory input during treatment

- motivation by family and possibly some reward system

- family offering social and financial support, e.g. private detoxification and personal allowances

- support network, e.g. voluntary sector and GP

- motivation to become drug-free and be employed, often within the family business

- relatively lower rate of alcohol use

- early engagement in treatment (approximately 67\% of Asian patients had an addiction history of 1-5 years).

However, these factors do not exclusively apply to Asian patients and may very well apply to White patients in different settings, locations and circumstances.

The importance of many of the considerations listed above was confirmed in the univariate analysis, whereby a significant effect was found for Asian or other minority ethnic status, employment or student status, low rate of boredom, motivation (borderline significance), supervision, addiction duration, cannabis use, younger age and lower alcohol intake favouring longer-term retention in treatment to 17 weeks or more (stage III). Subsequent multivariate analysis confirmed the considerable interrelationships between these variables. Sociodemographic factors such as ethnicity, employment status and supervision (reflecting family circumstances), boredom scores, cannabis use and age were no longer found to be significant influencers of naltrexone treatment efficacy.

Following multivariate analysis, duration of addiction of 7 or more years was identified as a significant predictor for poor outcome in terms of retention in treatment. This suggests that patients with prolonged addiction, even if well motivated to maintain abstinence, may require more intensive treatment strategies. It could be postulated that these patients have fewer close family ties following prolonged opioid addiction and therefore need greater support to continue with naltrexone treatment.

The exclusion criteria for this study included people with alcohol dependence or harmful use of alcohol, making the identification of a significant independent effect for alcohol use on retention in treatment for these patients of particular relevance. Additional support such as alcohol counselling may improve retention in treatment for patients who are heavy drinkers or report increasing alcohol intake during naltrexone treatment.

\section{Acknowledgements}

The authors wish to thank Paul Bassett, Statistician, who assisted in the final data analysis and Josie Saulter, Information Pharmacist, who helped with drafting the manuscript. 


\section{About the authors}

Zubair A. Chaudhry is Associate Specialist Psychiatrist at the Central and North West London NHS Foundation Trust. Javaid Sultan is Consultant Psychiatrist at the Berkshire Healthcare NHS Foundation Trust. Farrukh Alam is Consultant Psychiatrist and Clinical Director at the Central and North West London NHS Foundation Trust.

\section{References}

1 National Institute for Health and Clinical Excellence. Naltrexone for the Management of Opioid Dependence. NICE Technology Appraisal Guidance 115. NICE, 2007.

2 Luty J. What works in drug addiction? Adv Psychiat Treat 2003; 9: 280-8.

3 Adi $Y$, Juarez-Garcia A, Wang D, et al. Oral naltrexone as a treatment for relapse prevention in formerly opioid-dependent drug users: a systematic review and economic evaluation. Health Technol Assess 2007; 11: iii-iv, 1-85

4 Minozzi S, Amato L, Vecchi S, Jowett S, Frew E, Day E, et al. Oral naltrexone maintenance treatment for opioid dependence. Cochrane Database Syst Rev 2006; 25: CD001333.

5 Roozen HG, de Waart R, van der Windt DA, Davoli M, Kirchmayer U, Verster A. A systematic review of the effectiveness of naltrexone in the maintenance treatment of opioid and alcohol dependence. Eur Neuropsychopharmacol 2006; 16: 311-23.

6 Johansson BA, Berglund M, Lindgren A. Efficacy of maintenance treatment with naltrexone for opioid dependence: a meta-analytical review. Addiction 2006; 101: 491-503.
7 Kirchmayer U, Davoli M, Verster AD, Amato L, Ferri A, Perucci CA. A systematic review on the efficacy of naltrexone maintenance treatment in opioid dependence. Addiction 2002; 97: 1241-9.

8 Cornish JW, Metzger D, Woody GE, Wilson D, McLellan AT, Vandergrift B, et al. Naltrexone pharmacotherapy for opioid dependent federal probationers. J Subst Abuse Treat 1997; 14: 529-34.

9 Rawson RA, Glazer M, Callahan EJ, Liberman RP. Naltrexone and behavior therapy for heroin addiction. NIDA Res Monogr 1979; 25: 2643.

10 Nunes EV, Rothenberg JL, Sullivan MA, Carpenter KM, Kleber HD. Behavioral therapy to augment oral naltrexone for opioid dependence: a ceiling on effectiveness? Am J Drug Alcohol Abuse 2006; 32: 503-17.

11 Bartu A, Freeman NC, Gawthorne GS, Allsop SJ, Quigley AJ. Characteristics, retention and readmissions of opioid-dependent clients treated with oral naltrexone. Drug Alcohol Rev 2002; 21: 335-40.

12 Greenstein RA, Evans BD, McLellan AT, O'Brien CP. Predictors of favorable outcome following naltrexone treatment. Drug Alcohol Depend 1983; 12: 173-80.

13 Sullivan MA, Rothenberg JL, Vosburg SK, Church SH, Feldman SJ, Epstein EM, et al. Predictors of retention in naltrexone maintenance for opioid dependence: analysis of a stage I trial. Am J Addict 2006; 15: 150-9.

14 Ochoa E, Madoz-Gúrpide A, Salvador E. Diferencias de genero en e tratamiento de la dependencia de opiaceos con naltrexone. [Gender differences in the treatment of the opiate dependence with naltrexone.] Actas Esp Psiquiatr 2008; 36: 197-20. 